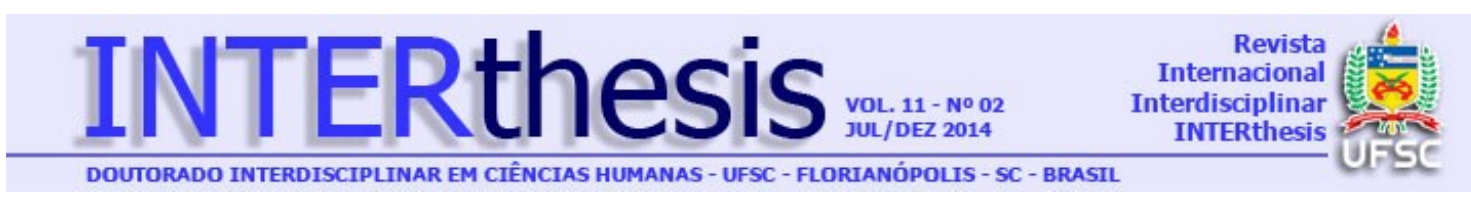

\title{
FAZER CIÊNCIA EM UMA ÉPOCA MARCADA PELA TECNOLOGIA ${ }^{1}$
}

Alberto Cupani

\section{Resumo:}

A tecnologia é hoje condição da maior parte da pesquisa científica, que se pratica em um mundo crescentemente tecnológico. Como resultado, a ciência tradicional, "acadêmica", endereçada a produzir conhecimento objetivo da realidade, vai sendo substituída pela denominada tecnociência, instrumento para alcançar finalidades extracientíficas. Essa mudança encerra riscos para a qualidade do conhecimento científico e ameaça a expectativa de que a ciência contribua para resolver adequadamente nossos problemas, pois o predomínio social da mentalidade tecnológica os reduz a questões técnicas.

Palavras-chave: Tecnociência. Tecnologia como condição da ciência. Ciência e problemas humanos.

A tecnologia está presente em quase todas as nossas atividades, afetando-as diversamente. A ciência não escapa a essa influência. Aspiro neste artigo a explicitála, mas para tanto, é necessário esclarecer o que vamos entender aqui por ciência e por tecnologia.

"Ciência" é, como muitas palavras, uma expressão ambígua, podendo significar conforme os contextos uma atividade social, endereçada à produção de certo tipo de conhecimento, ou bem o conhecimento por ela produzido. "Ciência" designa também uma entidade que muda, como tudo quanto existe, evoluindo de uma maneira específica decorrente do objetivo que lhe é próprio, porém não apenas dele, pois está sujeita às condições em que existe (uma das quais é hoje, precisamente, a tecnologia). "Ciência" é, além do mais, o nome de uma instituição

\footnotetext{
${ }^{1}$ Este texto foi elaborado baseado na Aula Inaugural do $2^{\circ}$ Semestre de 2014 do Programa de Pósgraduação Interdisciplinar em Ciências Humanas - Doutorado em Março de 2014 na Universidade Federal de Santa Catarina, Florianópolis, SC, Brasil.

2 Doutor em Filosofia pela Universidad Nacional de Córdoba, Pós-doutorado na Universidade de Paris 7. Pesquisador do CNPq de 1987 a 2008. Lecionou em diversas universidades da Argentina e na Universidade Federal de Santa Maria no Brasil. Professor titular da Universidade Federal de Santa Catarina até sua aposentadoria em Março de 2013. A sua área de docência (graduação e pósgraduação) e pesquisa é a Filosofia da Ciência, investigando principalmente os seguintes temas: ciência e valores, racionalidade e objetividade da ciência, ciência e controle da Natureza, filosofia da tecnologia, epistemologia das ciências humanas, filosofia da História. Autores mais estudados: Thomas Kuhn, Mario Bunge, Paul Feyerabend, Hugh Lacey. E-mail: cupani.alberto@gmail.com
} 
social (análoga ao Direito, a Religião, a Educação), que é muito prestigiada em nossa época e cultura, mas não em todas (povos e épocas houve e há em que a sociedade é indiferente à ciência ou hostil a ela). Por fim, "ciência" pode referir-se a determinada atitude perante a realidade, diferente de outras atitudes, como a técnica, a religiosa ou a artística (o cientista busca conhecer, não modificar a realidade, reverenciá-la ou exprimir as vivências que ela the suscita). ${ }^{3}$ Essas diversas acepções de "ciência" estão obviamente intervinculadas. Conforme os casos, ao falar da ciência enfatizamos um desses significados. Convém perceber qual deles para entender o que se diz sobre a ciência, ou se discute a propósito dela. Aqui, o que direi consiste em explicar que essa atividade está mudando profundamente, e que essa mudança se reflete no conhecimento científico e no valor a ele atribuído. Tratarei de explicar por que e como foi ocorrendo a mudança da prática científica, de tal modo que a ciência como instituição e como atitude humana afasta-se de certa concepção tradicional da mesma.

Mas "tecnologia" é também um termo ambíguo. Ainda que a maioria das pessoas associe espontaneamente essa palavra com algum artefato sofisticado (aposto que celulares e computadores sejam os exemplos mais frequentes), "tecnologia" denota bem mais do que isso. Ela se refere também a sistemas de objetos (como a instalação elétrica em um prédio, o conjunto de dispositivos que permitem uma cirurgia, a internet ou o sistema defensivo de um país). Além dessa presença material (ou mais material), a tecnologia existe na forma de certo tipo de conhecimento, diferente do conhecimento científico, pois a tecnologia, embora suponha a ciência (à diferença da mera técnica), ${ }^{4}$ não se reduz a ciência aplicada. $\mathrm{O}$ saber científico é abstrato e genérico, precisando sempre ser adaptado para fins concretos, e a tecnologia implica invenção, que não está implícita naquele saber. Ademais, a tecnologia recorre a conceitos, procedimentos e modelos diferentes dos científicos. ${ }^{5}$ Objetos, sistemas e determinado conhecimento não esgotam, todavia, o significado de "tecnologia". Existem atividades especificamente tecnológicas:

\footnotetext{
${ }^{3}$ Refiro-me à denominada ciência básica. Esta caracterização entender-se-á melhor, espero, pela exposição a seguir.

${ }^{4}$ Hoje em dia, até os objetos que possibilitam atividades técnicas (um martelo ou uma faca, por exemplo), resultam de entidades e atividades tecnológicas (fábricas), porém na invenção original do martelo ou da faca não foi necessária a ciência, ao passo que um termômetro ou um forno microondas pressupõem conhecimentos científicos.

${ }^{5}$ Ver meu artigo "La peculiaridad del conocimiento tecnológico" (CUPANI 2006)
}

R. Inter. Interdisc. INTERthesis, Florianópolis, v.11, n.2, p.01-14, Jul-Dez. 2014
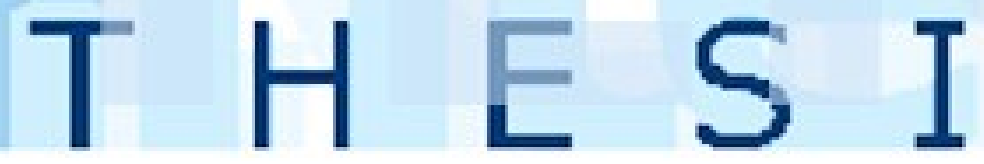
inventar, desenvolver, construir, testar, monitorar, reparar, usar, modificar (artefatos e sistemas) são práticas humanas diferentes de, por exemplo, meditar, rezar, amar, educar ou brincar. Por fim, a tecnologia, assim como a ciência, encarna uma atitude específica ante a realidade: no caso da tecnologia, a vontade de controlar a realidade natural ou social, presente já na técnica, porém enormemente potenciada. ${ }^{6}$ Neste artigo estarei referindo-me à maneira como o propósito de controle está subordinando na pesquisa científica o propósito de conhecimento. Isso tem a ver, certamente, com a circunstância de que a ciência esteve vinculada desde antigamente com as técnicas, e que a ciência moderna desenvolveu-se possibilitada pela tecnologia. Também, com o fato de que a ciência (natural) de ponta é impraticável sem recursos tecnológicos. No entanto, tudo isso não precisaria ter como consequência aquela subordinação, que constitui um perigo para a vida humana.

Tradicionalmente, a relação entre a ciência e a tecnologia foi concebida de maneira simplificada: a ciência gera tecnologia, a pesquisa endereçada a explicar os fenômenos do mundo acaba servindo, imediatamente ou não, para produzir transformações necessárias ou convenientes na vida humana, mediante artefatos que o mero engenho humano não poderia gerar. Porém, a relação da ciência com a tecnologia é bem mais complexa, pois a tecnologia faz parte das nossas vidas, não apenas pela onipresença de aparelhos (veículos, instrumentos, instalações), mas pela nossa inserção cada vez maior em sistemas tecnológicos (internet, ar condicionado, iluminação, circuitos de transporte), pela nossa crescente necessidade de lidar com artefatos e sistemas (aprender a usar dispositivos que exigem rapidez, obrigam a memorizar códigos e mudam com frequência), e pela difusão de uma mentalidade tecnológica, perceptível no vocabulário ("programar-se" para tal ou qual tarefa; "acessar" a informação da memória) e nas preferências das pessoas (as flores de plástico, "igualzinhas às naturais", não precisam de cuidados; o elevador evita o esforço de subir a escada e abrevia o tempo de deslocamento; o aspirador de pó limpa melhor). A comodidade, a economia, a velocidade e sobretudo a eficiência - valores tipicamente tecnológicos - norteiam cada vez mais as nossas existências.

${ }^{6}$ Para estas quatro modalidades da tecnologia ver MITCHAM 1994.

R. Inter. Interdisc. INTERthesis, Florianópolis, v.11, n.2, p.01-14, Jul-Dez. 2014
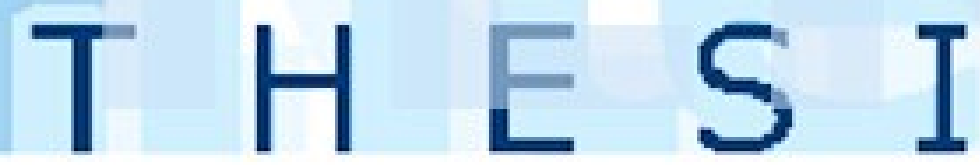
Como "fazer ciência" numa sociedade assim marcada pela tecnologia? Para começar, "fazer ciência" pode significar, ou bem de que modo, de fato, ocorre a pesquisa, ou bem de que modo deveria ocorrer. Neste trabalho estou interessado na relação entre as duas maneiras de entender aquela expressão. Ao refletir sobre a ciência, não estou me limitando a alguma disciplina ou algum tipo de pesquisa. Entendo por ciência todo tipo de pesquisa sistemática relativa a um determinado aspecto do mundo que visa a obter um conhecimento confiável acerca do mesmo dentro das pressuposições de determinada disciplina (seu "paradigma"). Assim entendida, a ciência inclui tanto a Física quanto a Economia, tanto a Geografia quanto a Psicologia. ${ }^{7}$ Já o conhecimento científico pode ser caracterizado como informação objetiva (ou seja, que corresponde à índole do que é pesquisado, e não necessariamente ao que se supõe ou deseja, individual ou grupalmente), pública (isto é, que vale para todos os que têm a devida competência), verificada (testada), crítica (e autocrítica), interpretada e julgada, e aperfeiçoável. A interpretação mencionada significa que o conhecimento não consiste em mero acúmulo de dados: eles devem ser entendidos em sua relevância (para a constatação de um fato, para o teste de uma hipótese, etc.), o que supõe que os cientistas devem apreciar essa relevância em função de determinados critérios. Essa operação não é algorítmica; exige experiência e suscita amiúde polêmicas antes que um resultado seja considerado como informação confiável sobre determinado aspecto do mundo. E todo resultado científico é, por definição, provisório, por mais que sua vigência seja às vezes duradoura (teoria, explicação ou descrição consideradas como satisfatórias). Naturalmente, tudo isso é alcançado tão somente em algum grau (o que se percebe precisamente pela crítica, as novas descobertas, os novos recursos).

A tecnologia condiciona a ciência moderna desde seus primórdios. Sem o telescópio e o microscópio ela não teria progredido, porém tampouco o teria feito sem o relógio e a balança de precisão, assim como o sistema métrico decimal (uma realização tecno-científica). A ciência natural de avançada depende essencialmente da tecnologia e é "puxada" por ela: os enormes aceleradores de partículas criam as

\footnotetext{
7 Embora nas ciências humanas não haja propriamente paradigmas unanimemente compartilhados, podem considerar-se como análogos a eles os consensos teórico-metodológicos próprios de determinadas escolas (marxismo, behaviorismo, funcionalismo, etc.). Em todos esses casos entendo que se pratica ciência.
}

R. Inter. Interdisc. INTERthesis, Florianópolis, v.11, n.2, p.01-14, Jul-Dez. 2014
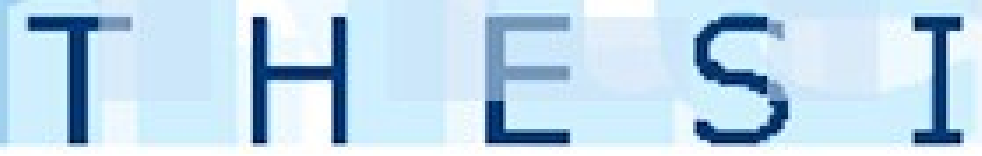
entidades que serão investigadas. Determinados resultados científicos, como a decifração do genoma humano, são ao mesmo tempo proezas tecnológicas. Prestando atenção a essa simbiose, torna-se particularmente convincente a tese de Lacey, conforme a qual a ciência moderna tem uma "afinidade eletiva" com a tecnologia, inclinando-se a preferir teorias que permitam o controle da Natureza (LACEY 2008-2010).

Esse tipo de saber enfrenta, notoriamente, questionamentos. Os pesquisadores de assuntos humanos amiúde rejeitam esse modelo de entendimento da realidade (a explicação mediante teorias causais), reivindicando como objetivo próprio de suas disciplinas a interpretação e compreensão do significado de comportamentos e obras. Alguns consideram igualmente necessária a crítica de aqueles fenômenos que consideram prejudiciais (como certas práticas e estruturas sociais), contrariando um modelo de ciência que se abstém de julgar o objeto de estudo. Os praticantes das ciências humanas objetam também, em alguns casos, a própria existência de paradigmas limitadores na investigação de uma realidade que é sempre mais complexa do que os "objetos" por eles definidos e os conceitos mediante os que os investigam (sejam eles "força", "função" ou "homo oeconomicus"). Esta objeção é particularmente relevante, é claro, para a pesquisa interdisciplinar.

A ciência (explicativa ou compreensiva) cultivada sem interesse na sua utilidade imediata existe ainda, ao menos nas universidades. Trata-se da chamada "ciência acadêmica", ou "modo 1" de obtenção de conhecimento (ZIMAN 2000, GIBBONS et alii 1994). No entanto, está sendo numericamente sobrepassada por outra modalidade de pesquisa: a "ciência pós-acadêmica" (Ziman), "modo 2 de conhecimento" (Gibbons et alii) ou mais comumente "tecnociência" (ECHEVERRÌA 2003). Consiste na pesquisa realizada ao serviço de projetos de finalidade prática: industrial, comercial, política, bélica. Em todos esses projetos, seja que se trate de produzir um novo remédio ou uma nova arma, de tornar mais competitivo uma mercadoria ou de consolidar uma política, o conhecimento é buscado, não pelo seu valor intrínseco (isto é, como melhor entendimento do mundo), mas pelo seu valor instrumental para a finalidade perseguida.

Ainda que a ciência aplicada seja uma prática antiga, a tecnociência ou "modo 2" de conhecimento, é relativamente nova. Conforme mostra Echeverria (op.cit.) a

R. Inter. Interdisc. INTERthesis, Florianópolis, v.11, n.2, p.01-14, Jul-Dez. 2014
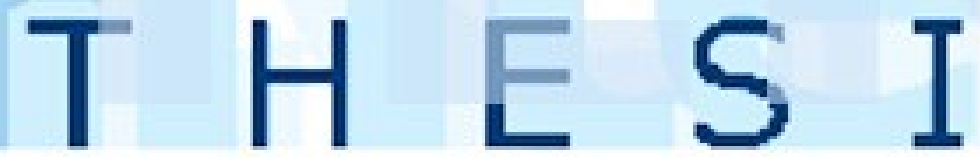
tecnociência derivou da "macrociência" (Big Science) cujo protótipo foi o Projeto Manhattan, idealizado para produzir a bomba atômica. ${ }^{8}$ Daquela época em diante, os Estados Unidos primeiro, e diversos outros países depois, começaram a planificar e financiar projetos de "pesquisa e desenvolvimento" com finalidades econômicas, educacionais, médicas e militares. Como toda pesquisa requer financiamento, é compreensível que os cientistas tenham migrado em muitos casos de projetos em ciência básica para projetos tecnocientíficos, embora isso signifique nada menos que a perda da autonomia científica, vale dizer, da liberdade de escolher assuntos de pesquisa tão somente pelo seu mérito em termos de um campo de conhecimento (física, biologia, etc.).

A tecnociência implica mudanças cruciais com relação à ciência tradicional, "acadêmica". Fundamentalmente, o fato de que o conhecimento deixa de ser um fim em si mesmo, fim esse que caracteriza a ciência, para se converter em um meio para outra finalidade. Quando em projetos tecnocientíficos acaba produzindo-se também avanços em ciência pura, isto ocorre como subproduto de procedimentos que têm outra finalidade. A segunda mudança importante consiste em que o sujeito da pesquisa já não é a comunidade de pesquisadores, mas a comunidade maior constituída pelos diversos agentes que intervêm no projeto (cientistas, engenheiros, técnicos, advogados, administradores, políticos, especialistas em marketing, psicólogos, representantes de comunidades afetadas por um problema, etc., conforme os casos). Todos eles, subordinados à autoridade de quem outorga ou administra os recursos financeiros (e com eles, os prazos da pesquisa). Uma terceira mudança implicada pela tecnociência reside no caráter trans, multi ou pluridisciplinar da pesquisa. Ainda que nem todos os agentes que intervêm num projeto tecnocientífico sejam pesquisadores (científicos ou tecnológicos), estes últimos são forçados a uma colaboração que põe em questão a utilidade dos conceitos, modelos e teorias procedentes dos seus respectivos campos e obriga à elaboração de ferramentas teóricas e metodológicas novas, de caráter híbrido. Em quarto lugar, e não porque seja o menos importante, dessa nova situação resulta que a avaliação do conhecimento a ser produzido não responde a puros critérios epistêmicos, mas também a outros como a urgência de resultados, a

\footnotetext{
${ }_{8}^{8}$ No âmbito industrial, o paralelo encontra-se na planificação científico-técnica da empresa Du Pont para produzir o nylon (ECHEVERRIA 2003:128).
}

R. Inter. Interdisc. INTERthesis, Florianópolis, v.11, n.2, p.01-14, Jul-Dez. 2014
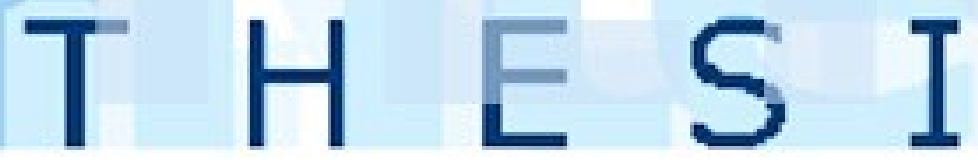
competitividade entre empresas e nações, o lucro, ou a necessidade de alcançar reconhecimento de direitos. $\mathrm{O}$ risco de que nesses casos o conhecimento resultante esteja enviesado é evidente. Resultados provisórios impostos pela necessidade de cumprir com prazos, dados epistemicamente duvidosos porém úteis, teorias superadas e não obstante eficientes em um determinado nível de operação, têm na tecnociência uma chance de aceitação que não teriam na ciência acadêmica. ${ }^{9} \mathrm{E}$ mesmo que não se chegue a esses extremos, a pesquisa tecnocientífica modifica os critérios de produção do conhecimento científico antes mencionados. A sua objetividade não significa já adequação à índole de uma realidade dada, mas a uma realidade produzida. O seu caráter público não significa que todos os cientistas de certa especialidade (por exemplo, a química orgânica ou a psicologia experimental) entendam, tão somente pela sua competência profissional, o conhecimento gerado para alcançar um resultado prático, pois esse conhecimento é agora heterogêneo e adaptado. A verificação da informação (colheita e manipulação de dados) é feita amiúde por aparelhos, não mais por pessoas. Isso aumenta a precisão, sendo muitos casos é a única maneira de proceder (v.gr., em razão de se trabalhar com dados muito numerosos, a serem processados rapidamente), mas reduz ou elimina a interpretação. Ou melhor: muda a índole da interpretação e do juízo que precede à aceitação de resultados, pois estes não são agora buscados com interesse puramente cognitivo, mas pela sua conveniência prática. Pela mesma razão muda o tipo de crítica e autocrítica que acompanha o saber científico. Para começar, os resultados estritamente científicos da pesquisa não são considerados de posse comum a todos os interessados, mas protegidos pelo segredo (característico da pesquisa industrial e bélica). Além do mais, a crítica interna é feita apelando a critérios de aceitabilidade prática, e igualmente é feita a autocrítica dos profissionais envolvidos. ${ }^{10} \mathrm{E}$ por esse seu caráter prático, particularizado, vinculado a situações concretas (por mais que possam afetar grandes territórios ou populações), os resultados tecnocientíficos são aperfeiçoáveis num sentido diferente dos resultados da ciência tradicional.

\footnotetext{
9 Isso não implica que os defeitos, as negligências, os preconceitos e as fraudes não possam ocorrer na ciência acadêmica efetiva. Apenas que nesta última são em princípio inadmissíveis.

${ }_{10}$ Com outras palavras: o resultado de um teste de materiais empregado na fabricação de um novo tipo de automóvel, por exemplo, não será apreciado em relação ao que se considera válido na física ou ainda na ciência dos materiais, mas em relação com a finalidade de produzir aquele veículo.
}

R. Inter. Interdisc. INTERthesis, Florianópolis, v.11, n.2, p.01-14, Jul-Dez. 2014
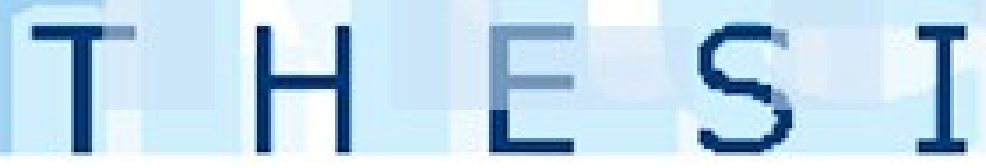
Em tudo e por tudo, a tecnociência parece o contrário da ciência básica ou acadêmica. Esta última responde, supostamente, aos "imperativos institucionais" que R. Merton achou formuláveis como: comunalismo (os resultados científicos não são propriedade de ninguém), universalismo (o conhecimento deve ser acessível a todo aquele que possua a competência necessária), desinteresse (com relação a todo objetivo que não seja a obtenção de conhecimento) e ceticismo organizado (exposição das reivindicações de conhecimento ao juízo crítico da comunidade profissional) (MERTON 1973). A tecnociência é inspirada por um ethos bem diferente: o conhecimento que gera é proprietário (no sentido de ter dono, de ser patenteado), é local, encomendado e especializado. Obviamente, a pesquisa já não é mais desinteressada (ZIMAN 2000:78). ${ }^{11}$

Não raramente, esse novo tipo de pesquisa é criticado pelos defensores da ciência acadêmica por constituir uma deturpação da ciência, indevidamente mercantilizada e politizada. Os entusiastas da tecnociência, por sua vez, consideram-se realistas quanto à forma em que a ciência deve ser praticada para se justificarem os investimentos que demanda e para que responda adequadamente aos problemas que a sociedade enfrenta. $O$ pretenso desinteresse prático da ciência acadêmica (não poucas vezes denunciado como falso) ${ }^{12}$ é visto antes como indiferença para com as necessidades humanas. O conflito entre partidários de cada uma dessas modalidades de pesquisa (um aspecto da denominada "guerra das ciências", ou seja, da discussão política do alcance epistêmico e do significado cultural da ciência) faz com que muitos cheguem a uma conclusão relativista: a ciência não seria mais do que uma ideologia entre outras, particularmente poderosa por encarnar e sustentar o espírito da Modernidade europeia, cujo imperialismo converteu-se na atual globalização, e particularmente útil pela sua associação com o capitalismo. Quando não se chega a esse extremo, reivindica-se o caráter "engajado" da ciência, a necessidade de que ela esteja a serviço de outros interesses que aqueles dos donos do poder. É o caso da ciência instrumentalizada pelos grupos sociais em busca de "empoderamento", às vezes na forma de proposta

${ }^{11}$ Acrescente-se que os cientistas assumem uma mentalidade empresarial (quando lideram projetos e procuram obter financiamentos) e fabril (quando se reduzem a trabalhar como operários dentro do projeto).

12 No sentido de que os cientistas dificilmente pesquisariam algum assunto se contassem com a (impossível) garantia de que jamais terá, de qualquer ponto de vista, utilidade alguma.

R. Inter. Interdisc. INTERthesis, Florianópolis, v.11, n.2, p.01-14, Jul-Dez. 2014
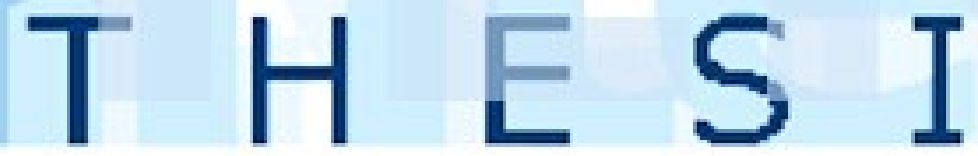
de outro tipo de pesquisa, que combine saber especializado e saber vulgar, e que permita a participação dos leigos de forma democrática (ver COMSTOK 2001). Outra reação, enfim, consiste na defesa da pesquisa tradicional, disciplinar, vista como única maneira de que a ciência não degenere em mera justificação da ação política. Cabe lembrar que esta opção tropeça com a dificuldade, cada vez maior, de abordar questões que ultrapassam o âmbito de uma disciplina, questionando os perfis e limites das disciplinas e exigindo algum tipo de colaboração interdisciplinar.

As observações anteriores correspondem ao que "fazer ciência" representa de fato, e às suas consequências. Mas, como adiantei, "fazer ciência" significa também a maneira em que a ciência deveria ser praticada. É necessário por isso lembrar agora o ideal da ciência formulado pelo lluminismo como condição do progresso humano. Com efeito, e como é sabido, os pensadores da Aufklärung sustentaram que a ciência devia ser o grande instrumento para a constante melhoria da vida humana. O aumento sistemático do conhecimento confiável sobre o mundo natural e humano, acreditavam, iria ter como resultado não apenas o crescimento intelectual, mas também o aperfeiçoamento moral e político da humanidade. Devido às limitações da concepção iluminista da racionalidade (refiro-me à sua ignorância dos fatores inconscientes que pesam sobre o exercício da razão, e à sua subestimação da importância dos condicionamentos sociais desse exercício), não conseguiram prever que uma sociedade "científica" podia ser em diversos aspectos irracional e incluir modos de comportamento individual e coletivo (como a violência exacerbada e os prejuízos massivos ao meio ambiente) que seria impossível visualizar como melhores em comparação com seus equivalentes de épocas passadas. Por outra parte, a crítica da ciência ${ }^{13}$ tornou evidente que o que podemos denominar História oficial da ciência, que a apresenta como evolução do conhecimento desinteressado da realidade, superando constantemente prejuízos "obscurantistas" e servindo para propósitos úteis, constitui uma idealização. Ao olhar crítico, a marcha histórica da ciência ocidental revela-se como um processo complexo em que a pesquisa foi sempre "humana, demasiado humana", misturada a especulações metafísicas, lastrada por influências sociais não percebidas, sujeita a disputas de poder e servindo amiúde a propósitos extracientíficos tanto quanto aos científicos, de Arquimedes a Einstein, passando por Galileu.

${ }^{13}$ Refiro-me a críticas diversas: as das feministas, às da "contracultura", às "pós-modernas", etc.

R. Inter. Interdisc. INTERthesis, Florianópolis, v.11, n.2, p.01-14, Jul-Dez. 2014
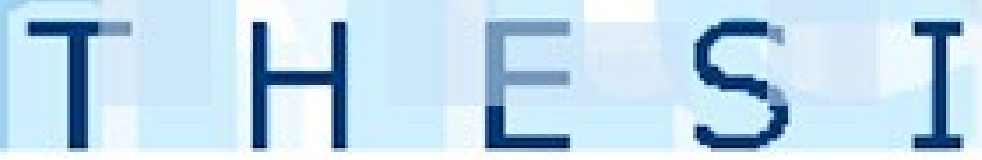
Sem embargo, acho necessário distinguir entre essa idealização e o ideal em causa. Perseguir um conhecimento confiável da realidade como base de uma vida melhor parece-me um ideal irrenunciável. Que esse conhecimento deva ser alcançado de maneira sistemática, em princípio pelos procedimentos (crítica, observação, cálculo, demonstração, etc.) que consideramos característicos da ciência, é uma convicção difícil de ser substituída. O prova o fato de que a ciência é invocada em caso de dúvidas e conflitos. De maneira crescente, o cientista é convidado, convocado ou contratado, segundo os casos, na condição de assessor ou conselheiro (adviser) de empresas, governos e grupos sociais. Trata-se do "uso não instrumental" da ciência (Ziman), cuja importância não deve ser subestimada. É claro que persistem aqui possíveis mal-entendidos. A opinião do cientista não é como às vezes ingenuamente se espera - "a voz da verdade" que resolve o problema (seja ele o da preservação de uma floresta ou o da mais eficaz propaganda de um lançamento comercial). Os cientistas amiúde divergem legitimamente ao diagnosticar uma situação, se equivocam ou estão inconfessadamente comprometidos com determinado interesse em jogo. Ainda assim, um auxílio científico eficaz e razoavelmente isento não é impossível (ver PIELKE 2007).

Precisamos, por isso, confiar na prática da ciência endereçada a entender o mundo, não porque acreditemos na ciência literalmente desinteressada, mas porque precisamos distinguir a obtenção de conhecimento confiável dos usos que julgamos objetáveis ou francamente prejudiciais, e precisamos contar com esse conhecimento para enfrentar os problemas que nos preocupam (inclusive, o mal uso ou a prática equivocada da ciência) e alcançar os objetivos que desejamos. Trata-se de resgatar a confiança na importância do saber para o bem viver. ${ }^{14}$ Esse exercício da ciência supõe amiúde o uso de tecnologias, porém o conhecimento que buscamos nem sempre está garantido pelo uso de tecnologias. Tem mais a ver com nossa sensibilidade para o que exige o tipo de fenômeno a ser investigado e não se

\footnotetext{
${ }^{14}$ Esse resgate não significa, a meu ver, que o conhecimento científico seja mantido, à maneira dos positivistas clássicos, como única ou melhor forma de saber válido. Consiste em identificar aquilo que, na resolução de um problema ou no alcance de uma meta, depende de conhecimentos objetivos, sistematicamente obtidos, e não de convicções, pontos de vista, etc. (ainda que estes elementos possam ser também significativos).
}

R. Inter. Interdisc. INTERthesis, Florianópolis, v.11, n.2, p.01-14, Jul-Dez. 2014
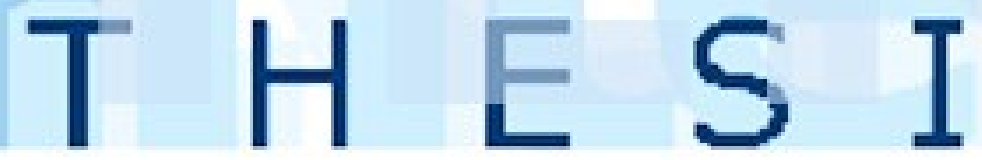
compromete necessariamente com o controle da realidade, propósito típico da tecnologia.

Para finalizar, vejamos quais são as vantagens que o uso de tecnologias representa para a pesquisa científica, e em que sentido essas vantagens podem constituir uma ameaça à integridade da ciência e à conduta humana fundamentada na ciência.

Recursos tecnológicos permitem conhecer mais e novos fenômenos, evidenciando a complexidade do "simples". Essa constatação, que remonta ao uso inicial do telescópio e do microscópio, vale para inúmeros recursos mais sofisticados de que hoje dispomos (aceleradores de partículas, espectrógrafos, magnetos, etc.). Os recursos tecnológicos aumentam a precisão e a fidelidade dos dados (na medida em que reduzem as alterações decorrentes da subjetividade humana). Facilitam também o "cruzamento" de informação, em grande quantidade e velocidade (o uso cada vez mais estendido de programas de computador em pesquisas naturais e sociais dispensa maiores comentários). A tecnologia permite registrar e retomar fenômenos de novas maneiras (como nas diversas formas de gravação e filmagem), o que, entre outros benefícios, amplia a "conservação" do passado. A tecnologia possibilita igualmente "simular" situações e eventos, ampliando a projeção do futuro. De modo geral, o uso de tecnologias aumenta a eficiência dos procedimentos (valor central da tecnologia).

Mas o recurso à tecnologia pode prejudicar a qualidade da pesquisa, principalmente pela tendência a reduzir o conhecimento à produção e manipulação de mera informação carente de organização, desprovida de interpretação, crítica e juízo humano. ${ }^{15} \mathrm{O}$ fato de que essa informação imatura, amiúde excessiva e até caótica seja confundida com conhecimento da realidade em questão é reforçada pela ilusão de que os dados e resultados tecnológicos são seguros e que a objetividade da ciência exige a exclusão de toda subjetividade. Prejuízo ainda maior decorre da redução (característica da mentalidade científica associada à tecnologia) de todo tipo de problemas práticos humanos a questões técnicas. Uma questão técnica (seja ela escolher um parafuso adequado, localizar uma fratura óssea ou calcular a velocidade necessária para um foguete espacial) pode ser bem definida,

${ }^{15} \mathrm{Em}$ contraposição às características da informação que constitui genuíno conhecimento, como sustentei antes.

R. Inter. Interdisc. INTERthesis, Florianópolis, v.11, n.2, p.01-14, Jul-Dez. 2014
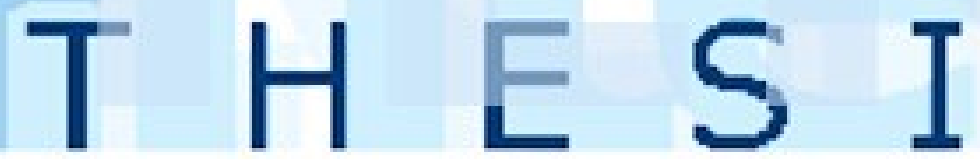
eficientemente abordada e convenientemente resolvida. Qualquer falha em uma dessas etapas pode, em princípio, ser superada. Mas o vasto campo da existência humana inclui questões que não são técnicas: preocupações existenciais, dilemas morais, dificuldades pedagógicas, conflitos sociais e decisões políticas são exemplos de situações em que um enfoque técnico ou tecnicista (como na tecnocracia, ou no tratamento de todo problema psíquico exclusivamente com base em medicamentos) é equivocado. Tais questões podem, eventualmente, requerer certa dose de tecnologia (como no caso da didática facilitada por instrumentos audiovisuais, ou nas terapias que recorrem a testes psicológicos), porém sua solução não é tecnológica. Sobrepor-se a uma crise de identidade, agir de maneira justa, adquirir uma habilidade, conseguir que se supere um preconceito ou conduzir satisfatoriamente um país não equivalem a produzir um dispositivo ou a gerar um procedimento que funcione bem. Algumas dessas questões talvez nem tenham solução na forma de um produto, resultado final, data de conclusão ou resposta satisfatória. Elas podem terminar em transformações cujo momento crítico não é advertido, em mudanças reconhecidas como tais apenas futuramente, em decisões eticamente corretas de maneira inovadora... E elas podem terminar (terminar?) também em fracasso, abandono, esquecimento, pois nem tudo na vida se resolve (muito menos, tecnologicamente).

R. Inter. Interdisc. INTERthesis, Florianópolis, v.11, n.2, p.01-14, Jul-Dez. 2014
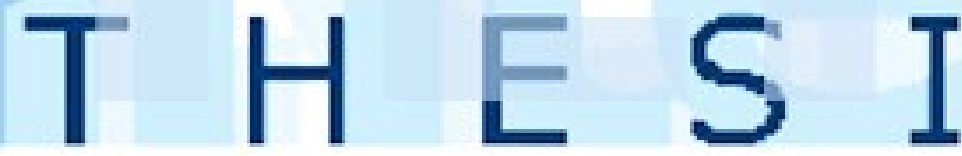


\title{
DOING SCIENCE IN A TECHNOLOGICAL TIME
}

\begin{abstract}
:
Technology is nowadays condition of most scientific research, which is done in an increasingly technological world. As a result of it, traditional "academic" science that aims at producing objective knowledge is replaced by the so called technoscience, an instrument for achieving extra scientific goals. This change implies risks for the quality of scientific knowledge and threatens the expectation that science would help to solve human problems properly, because the social dominance of a technological mentality reduces them to technical issues.
\end{abstract}

Keywords: Technoscience. Technology as condition of science. Science and human problems.

\section{HACER CIENCIA EN UNA ÉPOCA MARCADA POR LA TECNOLOGIA}

\section{Resumen:}

La tecnología es hoy condición de la mayor parte de la investigación científica, que se practica en un mundo crecientemente tecnológico. Como resultado, la ciencia tradicional, "académica", dirigida a producir conocimiento objetivo de la realidad, va siendo substituida por la denominada tecnociencia, instrumento para alcanzar finalidades extra científicas. Ese cambio implica riesgos para la calidad del conocimiento científico y amenaza la expectativa de que la ciencia contribuya para resolver adecuadamente nuestros problemas, pues el predominio social de la mentalidad tecnológica los reduce a cuestiones técnicas.

Palabras clave: Tecnociencia. Tecnologia como condición de la ciencia. Ciencia y problemas humanos. 


\section{REFERÊNCIAS}

COMSTOK, D.E. 2001 "A Method for Social Research", in: Readings in The Philosophy of Social Science, por M. Martin e L. C. Mclntyre (eds). Cambridge, MASS: The MIT Press, 2001 [1994]

CUPANI, A. 2006 "La peculiaridad del conocimiento tecnológico", in Scientiae Studia, vol. 4, n. 3, p. 353-372.

GIBBONS, M., LIMOGES, C., NOWOTNY, H., SCHWARTZMAN, S., SCOTT, P. E TROW, M. 2010 [1994] The New Production of Knowledge. London: Sage.

LACEY, H. 2008-2010 Valores e Atividade Científica, volumes 1 e 2. São Paulo: Ed. 34.

MERTON, R. 1973 [1942] "The Normative Structure of Science", in: The sociology of science and empirical investigation. Chicago: The University of Chicago Press, p. 286-324.

MITCHAM, C. 1994 Thinking through Technology. The Path between Engineering and Philosophy. Chicago: The University of Chicago Press.

PIELKE, R. A. 2007 The Honest Broker. Making Sense of Science in Policy and Politics. Cambridge: Cambridge University Press.

ZIMAN, J. 2000 Real Science. What it is, and what it means. Cambridge: Cambridge University Press.

\section{Artigo:}

Recebido em Outubro de 2014

Aceito em Novembro de 2014

R. Inter. Interdisc. INTERthesis, Florianópolis, v.11, n.2, p.01-14, Jul-Dez. 2014 